\title{
Intramural bronchogenic cysts of the esophagus and gastroesophageal junction: A case report
}

\author{
HAYATO MATSUDA $^{1}$, MITSUAKI ISHIDA ${ }^{1}$, CHIKA MIYASAKA ${ }^{1}$, TAKU MICHIURA ${ }^{2}$, \\ KENTARO INOUE ${ }^{2}$, MITSUGU SEKIMOTO ${ }^{2}$ and KOJI TSUTA ${ }^{2}$ \\ Departments of ${ }^{1}$ Pathology and Laboratory Medicine and ${ }^{2}$ Surgery, Kansai Medical University, \\ Hirakata, Osaka 573-1010, Japan
}

Received October 10, 2019; Accepted May 19, 2020

DOI: $10.3892 / \mathrm{mco} .2020 .2058$

\begin{abstract}
Bronchogenic cyst is a relatively rare congenital malformation that is often identified in the mediastinum. The occurrence of bronchogenic cysts in the intramural esophagus and gastroesophageal junction is rare. The present report describes three cases of intramural bronchogenic cysts of the esophagus and gastroesophageal junction and reviews the clinicopathological features of these lesions. A 35-year-old Japanese male (Case 1), a 50-year-old Japanese woman (Case 2) and a 34-year-old Japanese man (Case 3) presented with dysphagia, pharyngeal pain and heartburn, respectively. Upper endoscopic examination revealed submucosal tumors in the esophagus (Case 1 and 2) and gastroesophageal junction (Case 3). Subsequent endoscopic examination revealed perforation of the cyst into the surface of the esophageal mucosa (Case 2). Surgical resection was performed in all cases. Histopathological examinations revealed that the submucosal cysts were covered by respiratory-type ciliated epithelium without atypia. Cartilage and bronchial glands were not observed in any of the cases. The present review of the clinicopathological characteristics of bronchogenic cysts of the esophagus and gastroesophageal junction revealed that males and females were equally affected. The median age of the patients was 34.5 years with a wide age distribution. The most common main complaint was dysphagia. A pre-operative diagnosis of bronchogenic cyst is difficult because no specific imaging features are present. As surgical resection is recommended for this lesion, recognition of the clinicopathological features of bronchogenic cysts is important for an accurate pre-operative diagnosis.
\end{abstract}

Correspondence to: Dr Mitsuaki Ishida, Department of Pathology and Laboratory Medicine, Kansai Medical University, 2-5-1 Shinmachi, Hirakata, Osaka 573-1010, Japan

E-mail: ishidamt@hirakata.kmu.ac.jp

Key words: bronchogenic cyst, esophagus, gastroesophageal junction, ciliated epithelium

\section{Introduction}

Bronchogenic cyst is a relatively rare congenital malformation that develops from abnormal budding of the ventral foregut during the early stage of gestation (1). Histologically, the cyst wall is covered by respiratory-type ciliated epithelium that may include cartilage and bronchial glands (2). The location of the cyst is dependent on the stage of embryogenesis at which budding of the foregut occurs (1). The most common location of bronchogenic cysts is the middle and superior mediastinum, following the lung parenchyma $(1,2)$. Unusual locations of bronchogenic cysts include the thymus, pericardium, diaphragm, esophagus, stomach, and retroperitoneum (3-10).

Intramural esophageal bronchogenic cysts are rare, and only 25 cases have been reported in the English literature since 2000 (7,8,11-25). However, some cases of bronchogenic cysts in the mediastinum perforating into the esophagus have been described (26). Intramural bronchogenic cysts in the gastroesophageal junction are extremely rare (only 6 cases have been reported in the English literature) (27-32), and because of the rarity of intramural bronchogenic cysts in the esophagus and gastroesophageal junction, their unique clinicopathological features have not been well recognized. The treatment strategy for bronchogenic cyst is complete excision to avoid recurrence and rare malignant transformation $(33,34)$. Therefore, accurate pre-operative diagnosis is very important for treatment.

In this study, we report three new cases of intramural bronchogenic cysts in the esophagus and gastroesophageal junction and review the clinicopathological characteristics of these rare lesions.

\section{Case report}

Case 1. A 35-year-old Japanese man presented with dysphagia. Upper endoscopic examination revealed an esophageal submucosal tumor. Pre-operative computed tomography (CT) was not available in our hospital. Subsequently, thoracoscopic enucleation of the tumor was performed. Histopathological examination indicated that a cyst $(4.5 \times 4 \times 3.5 \mathrm{~cm}$ in diameter $)$ was located in the muscularis propria and contained exudative fluid (Fig. 1). The cyst wall was covered by respiratory 
type ciliated epithelium without atypia (Fig. 1 inset). Neither cartilage nor bronchial glands were observed in the cyst wall. On the basis of these results, the patient was diagnosed with an intramural esophageal bronchogenic cyst. The post-operative course was uneventful, and the cyst did not reoccur by CT over 3 years of medical follow-up.

Case 2. A 50-year-old Japanese woman presented with pharyngeal pain and dysphagia. Upper endoscopic examination revealed a submucosal tumor in the esophagus, and no surface mucosal abnormality was noted. CT demonstrated a submucosal tumor in the esophagus (Fig. 2A). Subsequent endoscopic examination showed that the submucosal tumor was perforating into the esophageal lumen. Therefore, she underwent thoracoscopic subtotal esophagectomy. Histopathological examination revealed that the cyst $(3.5 \times 2 \mathrm{~cm}$ in diameter) was located in the muscularis propria of the esophagus, and perforated into the surface squamous mucosa of the esophagus, accompanied by lymphoplasmacytic infiltration around the cyst (Fig. 2B). The cyst wall was covered by respiratory-type ciliated epithelium without atypia, and a few goblet cells were occasionally observed (Fig. 2B, inset). Neither cartilage nor bronchial glands were observed in the cyst wall. On the basis of these clinical findings, the patient was diagnosed with an intramural bronchogenic cyst perforating into the esophageal. The post-operative course was uneventful, and the patient was free from recurrence by CT during the 3 months of medical follow-up.

Case 3. A 34-year-old Japanese man presented with heartburn. Upper endoscopic examination demonstrated that a submucosal tumor $(4.5 \times 3.3 \mathrm{~cm}$ in diameter $)$ was located immediately under the gastroesophageal junction without a remarkable change on the surface of the gastric mucosa. Pre-operative computed tomography (CT) was not available in our hospital. Subsequently, enucleation of the tumor was performed. Histopathological analysis showed that a large cyst was present under the mucosa of the gastroesophageal junction (Fig. 3A and B) and its wall was covered by respiratory-type ciliated epithelium without atypia (Fig. 3B, inset). Neither cartilage nor bronchial glands were observed in the cyst wall. Accordingly, the patient was diagnosed as intramural bronchogenic cyst in the gastroesophageal junction. The post-operative course was uneventful, and the patient was free from recurrence by CT for 1 year of medical follow-up.

\section{Discussion}

In this article, we describe the clinicopathological features of three cases of intramural bronchogenic cysts in the esophagus and gastroesophageal junction. Table I summarizes the clinicopathological features of intramural bronchogenic cysts of the esophagus and gastroesophageal junction that have been reported since 2000 .

Among the 34 patients, men and women were equally affected. The median age of the patients was 34.5 years with a wide age distribution (from 3 days to 71 years) (Table I). The most common chief complaint was dysphagia with discomfort and pain, and no specific complaint for this lesion is present (Tables I and II). These symptoms may appear only when the

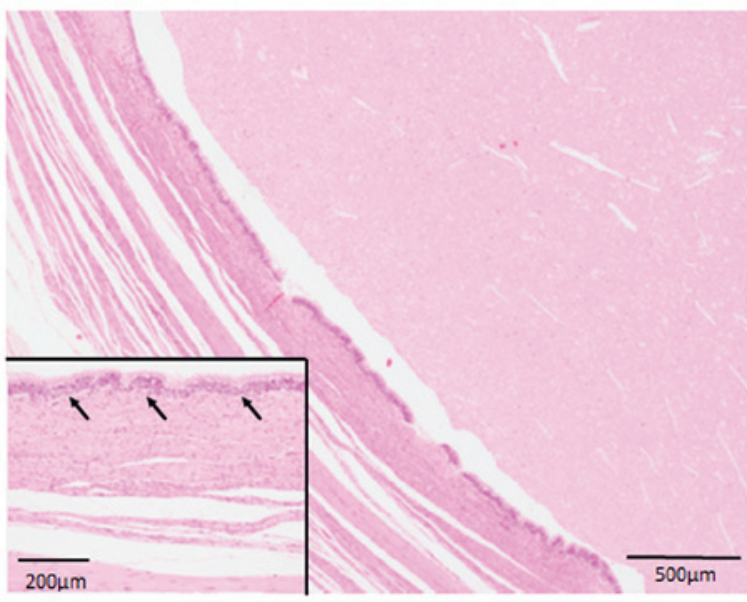

Figure 1. Histopathological features of the esophageal cyst (Case 1). The cyst was located in the muscularis propria and exudative fluid was present within the cyst. The cyst wall was covered by respiratory type ciliated epithelium without atypia (arrows; hematoxylin and eosin). Magnification, x100 and x200 (inset).
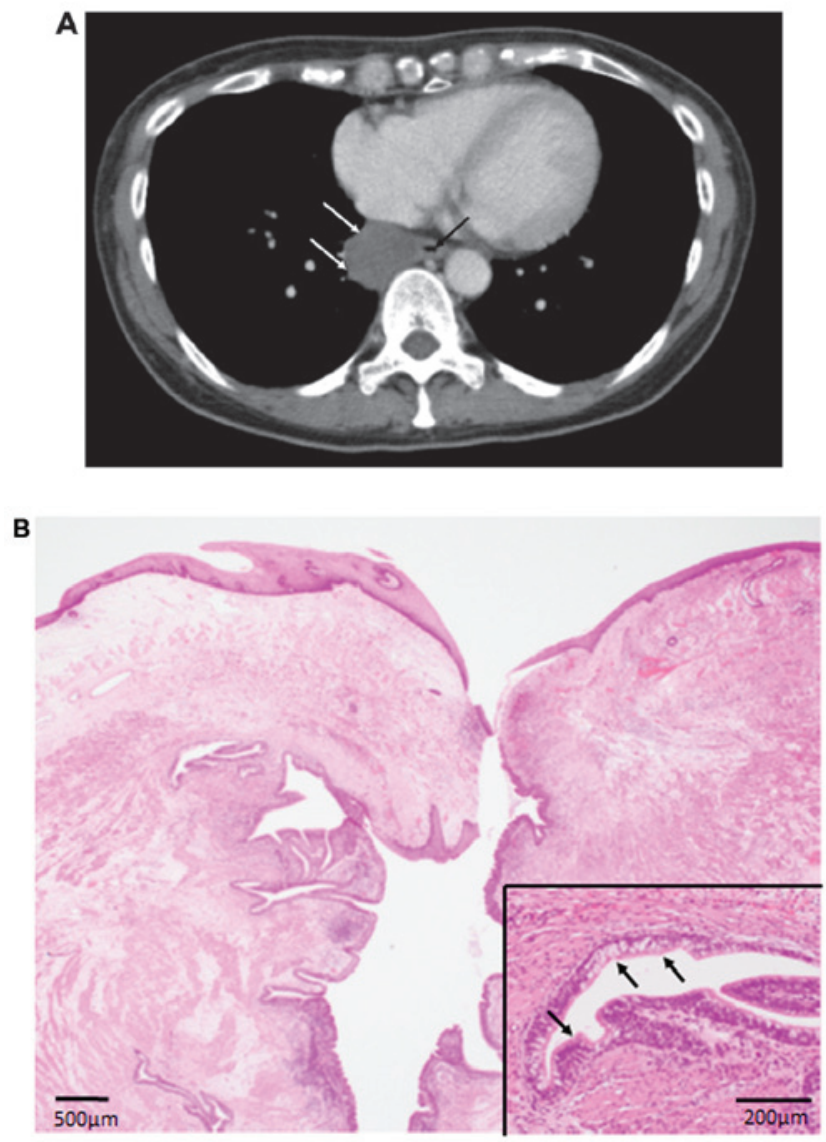

Figure 2. Computed tomography and histopathological features of the esophageal cyst (Case 2). (A) Well-circumscribed submucosal tumor of the esophagus (white arrows). Esophageal lumen was indicated by the black arrow. (B) The cyst was located in the muscularis propria of the esophagus, perforating into the surface squamous mucosa of the esophagus. The cyst was covered by respiratory-type ciliated epithelium without atypia, and goblet cells were occasionally observed (arrows, inset; hematoxylin and eosin stain). Magnification, x40 and x200 (inset).

cysts become larger, leading to compression of the esophagus and gastrointestinal junction. As most patients have small 


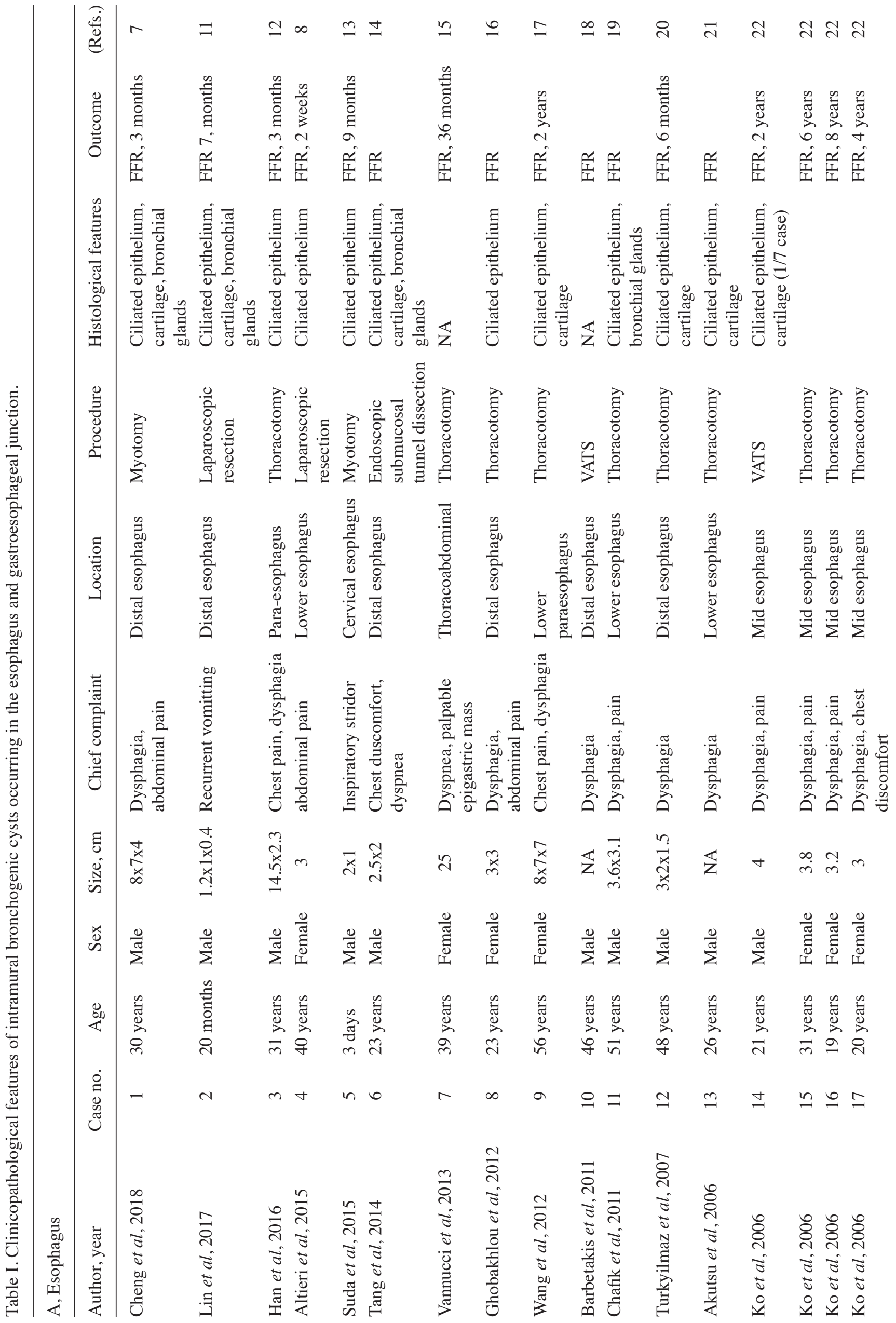



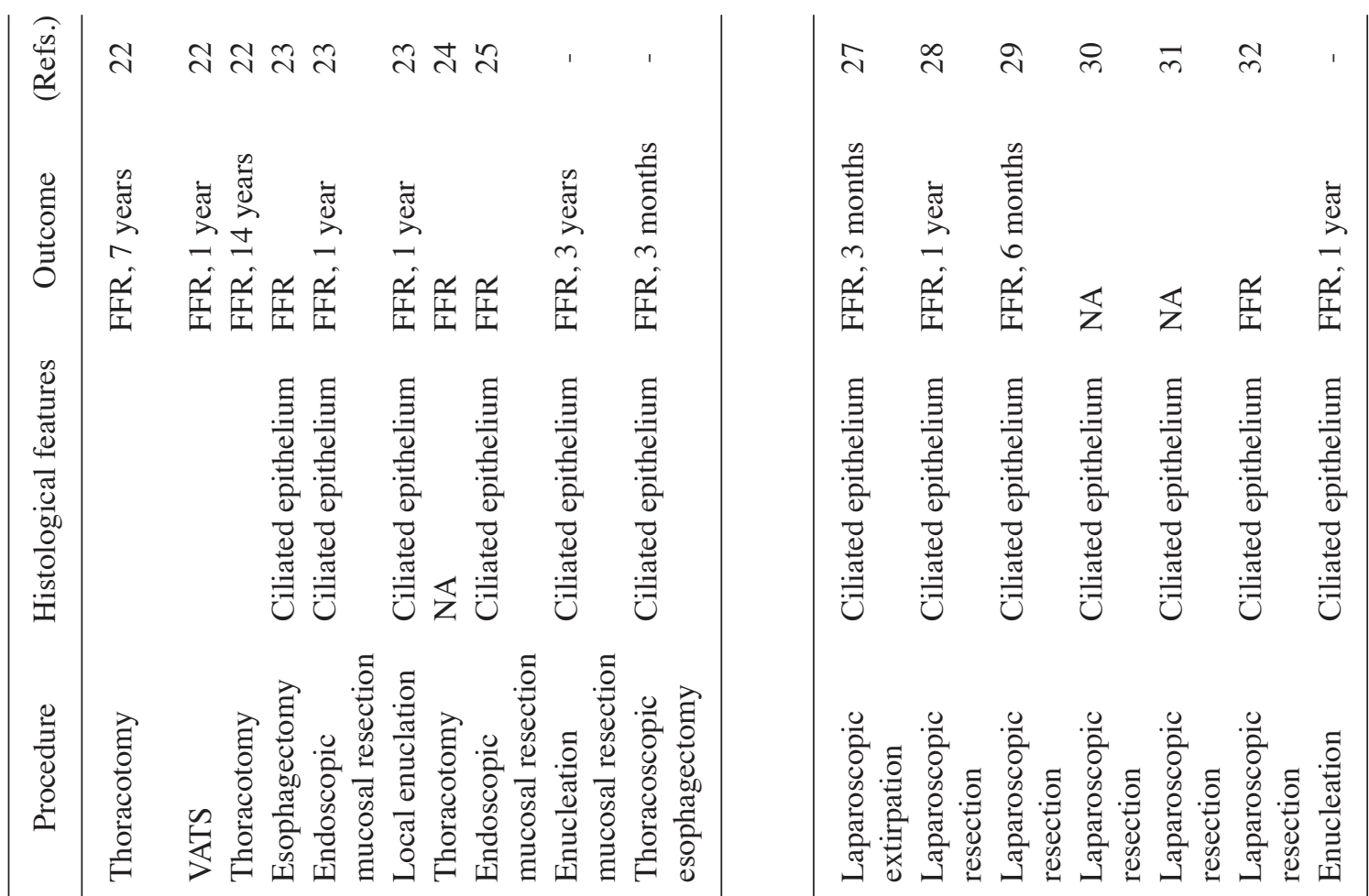

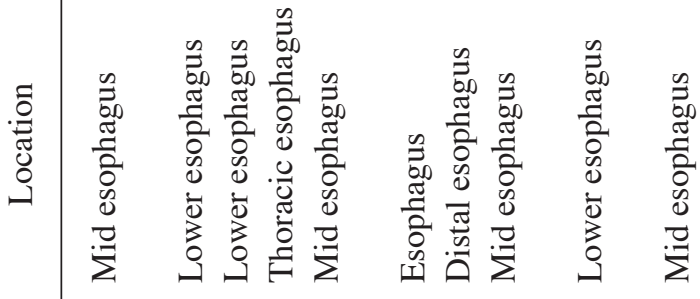

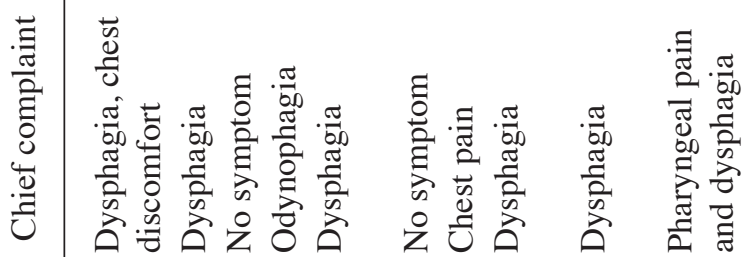

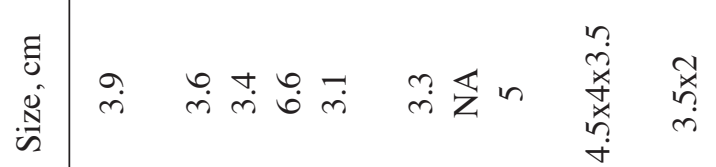

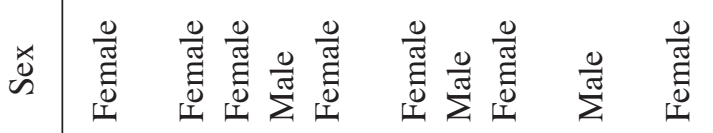

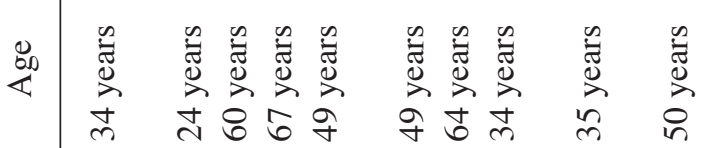

岂

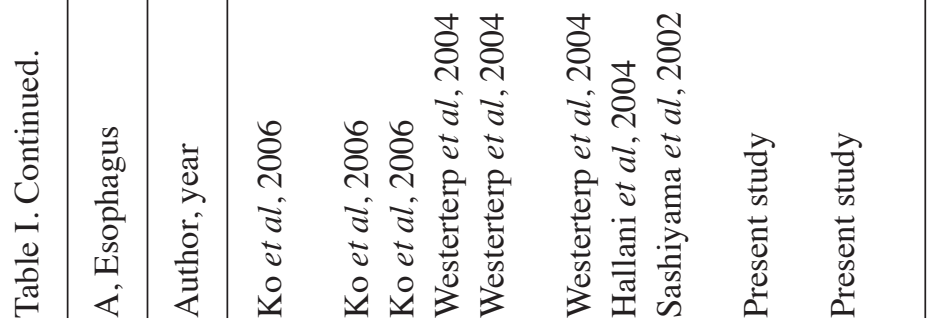

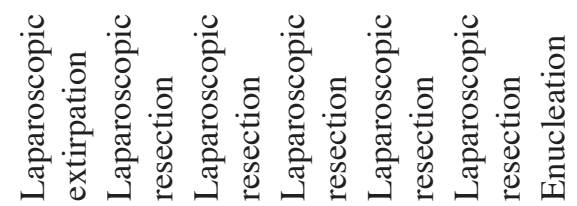

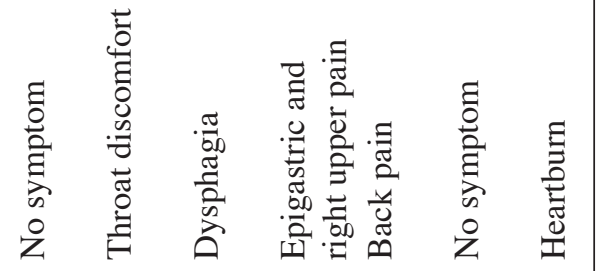

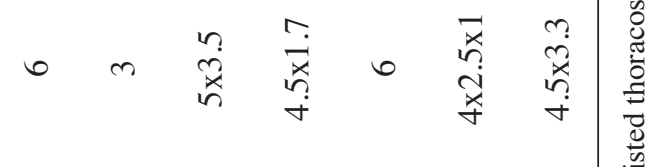

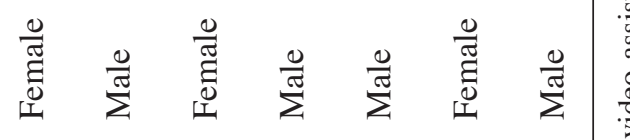

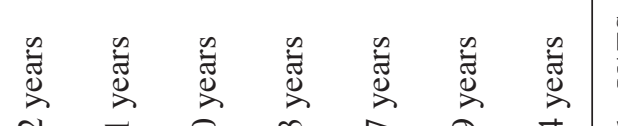
तै $₹$ के ले है के में

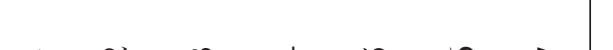

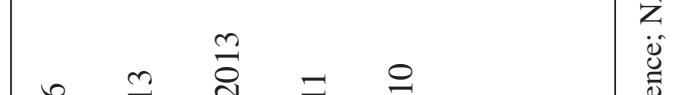

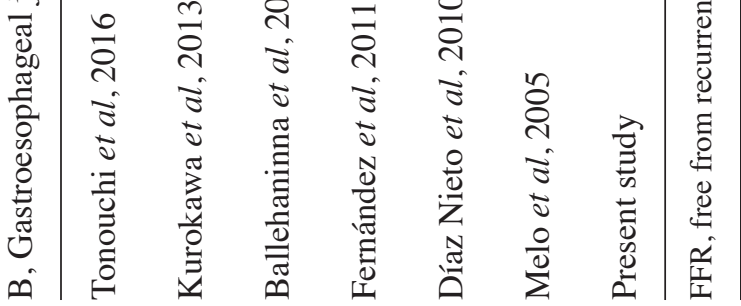


Table II. Summary of the main characteristics of intramural bronchogenic cysts.

\begin{tabular}{lclrlr}
\hline Symptoms & Patients, $\mathrm{n}$ & \multicolumn{1}{c}{ Histology } & Patients, $\mathrm{n}$ & \multicolumn{1}{c}{ Procedure } & Patients, $\mathrm{n}$ \\
\hline Dysphagia & 19 & Ciliated epithelium & 31 & Thoracotomy & 8 \\
Pain & 13 & Cartilage & 7 & Laparoscopic resection & 3 \\
No symptoms & 4 & Bronchial glands & 4 & VATS & 3 \\
Chest discomfort & 3 & & & Endoscopic submucosal resection \\
Dyspnea & 2 & & & Myotomy & 2 \\
\hline
\end{tabular}

A
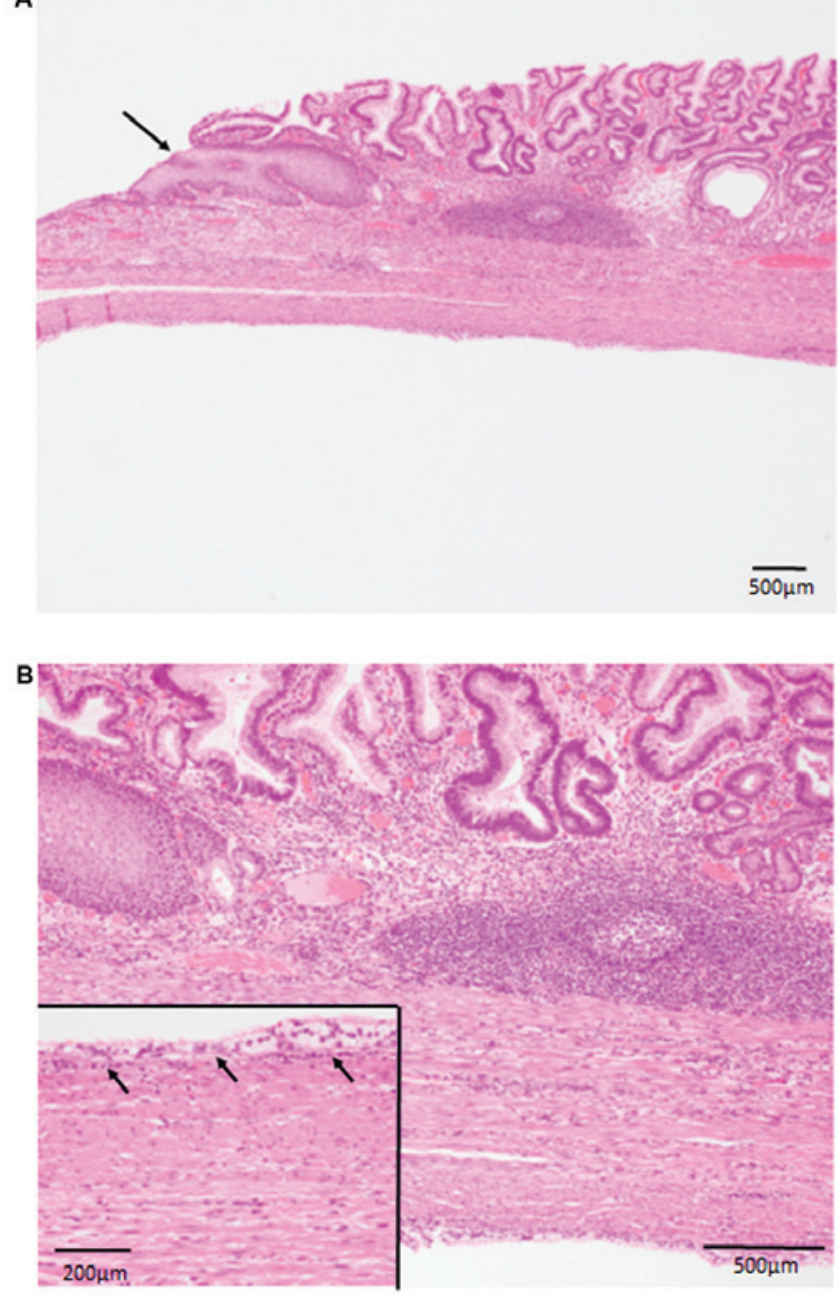

Figure 3. Histopathological features of the gastroesophageal cyst. (A) The cyst was located under the gastroesophageal mucosa [gastric type mucosa and squamous mucosa (arrow) were noted; H\&E stain]. Magnification, x40 (B) The cyst wall was covered by respiratory-type ciliated epithelium without atypia (arrows; H\&E stain). Magnification, x100 and x200 (inset). H\&E, hematoxylin and eosin.

asymptomatic cysts (7), the accurate morbidity of these lesions is unclear. Histopathologically, the respiratory-type ciliated epithelium was observed in all cases, and cartilage and bronchial glands were occasionally found in the cyst wall.

Accurate pre-operative diagnosis of bronchogenic cyst is very important for its appropriate treatment. The diagnosis of these lesions is challenging because they do not have specific imaging characteristics. Ko et al (22) reported the imaging characteristics of 7 cases of esophageal bronchogenic cysts. In the report, computed tomography $(\mathrm{CT})$ revealed that well-defined thin-wall cystic lesions were present within the esophageal wall. Furthermore, varied cyst densities were observed (because of the content of the cyst) without enhancement after administration of a contrast agent, and no intracystic solid content or abnormal air was identified (22). However, it may be difficult to distinguish intramural bronchogenic cysts from mediastinal masses, including lymphadenopathy or mediastinal tumors, compressed against the esophageal wall $(7,22)$. Furthermore, magnetic resonance imaging (MRI) showed variable signal intensities on T1-weighted images and a homogenous, high signal intensity on T2-weighted images (25).

Recently, endoscopic ultrasound (EUS) examination has been recognized as a useful tool for the diagnosis of bronchogenic cysts (7). EUS can identify whether the lesions of the esophagus and gastroesophageal junction are cystic or solid. Moreover, fine-needle aspiration (FNA) cytological examination using EUS can provide an even more accurate diagnosis because by this method it is possible to obtain a sample from the cyst wall. However, EUS-FNA may not be recommended for all patients with bronchogenic cysts because it can induce an infection, which would complicate the operation (7). The treatment strategy for bronchogenic cysts in the esophagus and gastroesophageal junction is complete resection (7). Therefore, a combination of the above-mentioned imaging techniques is required for an accurate pre-operative diagnosis of bronchogenic cyst.

The interesting finding of the present study is that one of bronchogenic cysts perforated into the esophageal lumen (Case 2). Only the second endoscopic examination detected the connection between the cyst and the surface mucosa of the esophagus. Therefore, secondary inflammation (probably due to infection) may have led to perforation of the cyst into the esophageal surface mucosa. Previous studies have already described an esophageal bronchogenic cyst with a connection to the surface squamous mucosa (17) and a mediastinal bronchogenic cyst perforated into the esophageal wall (26).

In conclusion, we reviewed the clinicopathological features of bronchogenic cysts in the esophagus and gastroesophageal junction. No specific symptoms or pre-operative imaging characteristics were present in this lesion, therefore, bronchogenic cyst must be added a list of differential diagnosis of the submucosal tumor of the esophagus and gastroesophageal junction. As surgical resection is recommended for this lesion, recognition of the clinicopathological features of bronchogenic cysts is important for accurate pre-operative diagnosis of this lesion. 


\section{Acknowledgements}

Not applicable.

\section{Funding}

No funding was received.

\section{Availability of data and materials}

All data generated or analyzed during this study are included in this published article.

\section{Authors' contributions}

HM, MI and CM conceived and designed the present study. HM, MI, CM, TM, KI, MS and KT collected and analyzed data. HM and MI drafted the manuscript and figures. All authors read and approved the final manuscript.

\section{Ethics approval and consent to participate}

The present study was conducted in accordance with the Declaration of Helsinki, and the study protocol was approved by the Institutional Review Board of Kansai Medical University Hospital (approval no. 2019050). Opt-out consent was obtained from each participant of this study.

\section{Patient consent for publication}

The need for informed consent was waived due to the retrospective design of the study, and opt-out consent was obtained from each participant of the present study.

\section{Competing interests}

The authors declare that they have no competing interests.

\section{References}

1. Berrocal T, Madrid C, Novo S, Gutiérrez J, Arjonilla A and Gómez-León N: Congenital anomalies of the tracheobronchial tree, lung, and mediastinum: Embryology, radiology, and pathology. Radiographics 24: e17, 2004.

2. Limaïem F, Ayadi-Kaddour A, Djilani H, Kilani T and El Mezni F: Pulmonary and mediastinal bronchogenic cysts: A clinicopathologic study of 33 cases. Lung 186: 55-61, 2008.

3. Hamouri S, Hatamleh M, Alaydi J, Alhadidi H, Alomari M, Aldaoud $\mathrm{N}$ and Darayseh B: Intra-thymic bronchogenic cyst an extremely rare tumor of anterior mediastinum in adults. J Cardiothorac Surg 13: 120, 2018.

4. Grozavu C, Fera A, Iliaş M and Pantile D: Intrapericardial development of a bronchogenic cyst-case report. Chirurgia (Bucur) 111: 345-349, 2016

5. Simonetti S, Canalís E, Macías L and Carrasco MA: Clinico-pathological features of the intradiaphragmatic bronchogenic cysts: Report of a case and review of the literature. Pathologica 110: 116-120, 2018.

6. Itoh H, Shitamura T, Kataoka H, Ide H, Akiyama Y, Hamasuna R, Hasui Y, Osada Y and Koono M: Retroperitoneal bronchogenic cyst: Report of a case and literature review. Pathol Int 49 : $152-155,1999$.

7. Cheng Y, Chen D, Shi L, Yang W, Sang Y, Duan S and Chen Y: Surgical treatment of an esophageal bronchogenic cyst with massive upper digestive tract hematoma without esophagectomy: A case report and the review of the literature. Ther Clin Risk Manag 14: 699-707,2018.
8. Altieri MS, Zheng R, Pryor AD, Heimann A, Ahn S and Telem DA: Esophageal bronchogenic cyst and review of the literature. Surg Endosc 29: 3010-3015, 2015.

9. Chhaidar A, Ammar H, Abdessayed N, Azzaza M, Gupta R, Abdennaceur N, Bdioui A, Mokni M and Ali AB: Large bronchogenic cyst of stomach: A case report. Int J Surg Case Rep 34: 126-129, 2017.

10. Tu C, Zhu J, Shao C, Mao W, Zhou X, Lin Q, Li Z, Zhang J, Zhou Q and Chen W: Gastric bronchogenic cysts: A case report and literature review. Exp Ther Med 11: 1265-1270, 2016.

11. Lin JS, Yu YR, Chiou EH, Chumpitazi BP, Schady DA and Brandt ML: Intramural esophageal bronchogenic cyst mimicking achalasia in a toddler. Pediatr Surg Int 33: 119-123, 2017.

12. Han C, Lin R, Yu J, Zhang Q, Zhang Y, Liu J, Ding Z and Hou X: A case report of esophageal bronchogenic cyst and review of the literature with an emphasis on endoscopic ultrasonography appearance. Medicine (Baltimore) 95: e3111, 2016.

13. Suda K, Sueyoshi R, Okawada M, Koga H, Lane GJ, Yamataka A and Doi T: Completely intramural bronchogenic cyst of the cervical esophagus in a neonate. Pediatr Surg Int 31: 683-687, 2015.

14. Tang X, Jiang B and Gong W: Endoscopic submucosal tunnel dissection of a bronchogenic esophageal cyst. Endoscopy 46 (Suppl 1): E626-E627, 2014.

15. Vannucci J, Pecoriello R, Tassi V, Ceccarelli S and Puma F: Giant thoracoabdominal esophageal bronchogenic cyst. Dis Esophagus 26: 340, 2013.

16. Ghobakhlou M, Fatemi SR, Dezfouli AA, Tirgary F and Zali MR: Long-term dysphagia due to bronchogenic cyst of the esophagus. Endoscopy 44 (Suppl 2): E129-E130, 2012.

17. Wang W, Ni Y, Zhang L, Li X, Ke C, Lu Q and Cheng Q: A case report of para-esophageal bronchogenic cyst with esophageal communication. J Cardiothorac Surg 7: 94, 2012.

18. Barbetakis N, Asteriou C, Kleontas A, Papadopoulou F and Tsilikas C: Video-assisted thoracoscopic resection of a bronchogenic esophageal cyst. J Minim Access Surg 7: 249-252, 2011.

19. Chafik A, Benjelloun A, Qassif H, El Fikri A, El Barni R and Zrara I: Intramural esophageal bronchogenic cysts. Asian Cardiovase Thorac Ann 19: 69-71, 2011.

20. Turkyilmaz A, Eroglu A, Subasi M and Findik G: Intramural esophageal bronchogenic cysts: A review of the literature. Dis Esophagus 20: 461-465, 2007.

21. Akutsu Y, Matsubara H, Hayashi H, Okazumi S, Aoki T, Kozu T and Ochiai T: Endoscope-assisted thoracoscopic technique for esophageal bronchogenic cyst which presented elevated CA125. Dig Surg 23: 209-214, 2006.

22. Ko SF, Hsieh MJ, Lin JW, Huang CC, Li CC, Cheung YC and Ng SH: Bronchogenic cyst of the esophagus: Clinical and imaging features of seven cases. Clin Imaging 30: 309-314, 2006.

23. Westerterp M, van den Berg JG, van Lanschot JJ and Fockens P: Intramural bronchogenic cysts mimicking solid tumors. Endoscopy 36: 1119-1122, 2004.

24. Hallani H, Eslick GD, Cox M, Wyatt JM and Lee CH: Chest pain? Cause. Lancet 363: 452, 2004.

25. Sashiyama H, Miyazaki S, Okazaki Y, Kaiho T, Nakajima Y, Hoshino T, Akai T, Nabeya Y, Funami Y, Shimada H, et al: Esophageal bronchogenic cyst successfully excised by endoscopic mucosal resection. Gastrointest Endosc 56: 141-145, 2002.

26. Rubin S, Sandu S, Durand E and Baehrel B: Diaphragmatic rupture during labour, two years after an intra-oesophageal rupture of a bronchogenic cyst treated by an omental wrapping. Interact Cardiovase Thorac Surg 9: 374-376, 2009.

27. Tonouchi A, Kinoshita T, Sunagawa H, Hamakawa T, Kaito A, Shibasaki H, Kuwata T, Seki Y and Nishida T: Bronchogenic cyst at esophagogastric junction treated by laparoscopic full-thickness resection and hand-sewn closure: A case report. Surg Case Rep 2: 41, 2016.

28. Kurokawa T, Yamamoto M, Ueda T, Enomoto T, Inoue $\mathrm{K}$, Uchida A, Kikuchi K and Ohkohchi N: Gastric bronchogenic cyst histologically diagnosed after laparoscopic excision: Report of a case. Int Surg 98: 455-460, 2013.

29. Ballehaninna UK, Shaw JP and Brichkov I: Subdiaphragmatic bronchogenic cyst at the gastroesophageal junction presenting with dysphagia: A case report. Surg Laparosc Endosc Percutan Tech 23: e170-e172, 2013.

30. Fernández JL, Bauza G and McAneny DB: Minimally invasive management of lesser sac bronchogenic cyst. JSLS 15: 571-574, 2011. 
31. Díaz Nieto R, Naranjo Torres A, Gómez Alvarez M, Ruiz Rabelo JF, Pérez Manrique MC, Ciria Bru R, Valverde Martínez A, Roldán de la Rúa J, Alonso Gómez J and Rufián Peña S: Intraabdominal bronchogenic cyst. J Gastrointest Surg 14: 756-758, 2010.

32. Melo N, Pitman MB and Rattner DW: Bronchogenic cyst of the gastric fundus presenting as a gastrointestinal stromal tumor J Laparoendosc Adv Surg Tech A 15: 163-165, 2005.

33. Fiorelli A, Rambaldi P, Accardo $M$ and Santini $M$ : Malignant transformation of bronchogenic cyst revealed by 99mTc-MIBI-SPECT. Asian Cardiovasc Thorac Ann 20: 347-349, 2012.
34. Taira N, Kawasaki H, Atsumi E, Ichi T, Kawabata T, Saio M and Yoshimi N: Mucoepidermoid carcinoma of arising from a bronchogenic cyst of the diaphragm. Ann Thorac Cardiovase Surg 24: 247-250, 2018 .

c) (1) $(\Theta$ This work is licensed under a Creative Commons Attribution-NonCommercial-NoDerivatives 4.0 International (CC BY-NC-ND 4.0) License. 